\title{
The impact of packaging transparency on product attractiveness
}

\begin{abstract}
The aim of the study was to investigate the impact of different levels of packaging transparency on the evaluation of attractiveness of a product within the packaging, in relation to whether it is a healthy or unhealthy product. Consumer preferences during buying decision process were also investigated. The study was conducted by two methods. The first one was related to consumer preferences and was based on a choice task, while the other one was related to packaging attractiveness and was based on subjective evaluation expressed through the Likert scale. Eight samples of packaging were used. They differed according to product type (healthy and unhealthy), and the level of transparency (fully transparent packaging, packaging with two windows, packaging with one window and non-transparent packaging). According to the results, consumers tend to ignore non-transparent packaging, regardless the product healthiness. The findings indicate the importance of thoughtful selection of packaging structure and its material in design process and launching the food products on the retail market.
\end{abstract}

\section{KEY WORDS}

packaging, transparency, attractiveness, product, preference

\author{
Barbara Sabo, \\ Tina Bečica, \\ Nikolina Keleš, \\ Dorotea Kovačević, \\ Maja Brozović \\ University of Zagreb, Faculty of \\ Graphic Arts, Zagreb, Croatia \\ Corresponding author: \\ Dorotea Kovačević \\ e-mail: \\ dorotea.kovacevic@grf.hr
}

First recieved: 22.05.2017. Accepted: 27.06.2017.

\section{Introduction}

Package design can have a significant role in users' perception of the product, considering their high demand criteria when choosing which product to buy. People are not only affected by visual components of packaging shape (Clement, Kristensen, \& Grønhaug, 2013; van Ooijen et al, 2017), color (Ares \& Deliza, 2010), typography (Karnal et al, 2016), but are also aware of the importance of the product information credibility and possibility of screening what is inside the package. In some extent, packaging transparency enables direct visual and tactile estimation, while the decrease or increase of its attractiveness may depend on the type of the product (Wasowicz-Kirylo \& Stysko-Kunkowska, 2011). According to Deng's \& Srinivasan's research (2013), there are two important factors that have the influence on consumption of the food product and come as a result of transparent packaging usage: visibility of the product and possibility of monitoring the product consumption. The first consequence of using transparent packaging is the visibility of the product. Another variable related to it is the visual attractiveness of the product inside. According to that, larger transparent surface doesn't necessarily result in an increase or decrease of product attractiveness in equal extent. For instance, highly transparent packaging of small, visually appealing products can increase the attractiveness and the consumption, while the result can be completely opposite in the case of the same packaging for a different group of products with large unit size. Moreover, packaging transparency can have a negative effect on product consumption as it offers the consumer a possibility to monitor it. Consequently, impulsive consumption can be prevented and the consumer is prone to think about it, plan it and distribute it in order to spare.

Some previous researches give a starting point for our research questions that are related to customer preferences and their perception of packaging attractiveness, considering the level of its transparency. The 
preferences and the attractiveness are in the focus of our study. In the form of the hypothesis, these variables are brought in relation to packaging transparency and type of product. The basis for the formation of the hypotheses is described below.

\section{Problem statement}

It's known that users form their attitude towards a product at the basis of the packaging (Becker et al, 2011; Metcalf et al, 2012; Wang, 2013). For example, one study (Chandran, Batra, \& Lawrence, 2009) showed that the product is perceived as a higher quality product if it is packed in a transparent bottle. The perception of the quality is closely linked to the preferences. Those depend on many factors, and one of them is a possibility of the product identification, either through transparent packaging, either through lifelike visual reproduction of the product on the non-transparent material (Venter et al, 2011). Enabling the customers to see the product through transparent packaging significantly increases their satisfaction (Kim \& Lee, 2015), which indirectly can reflect on their tendency to choose the product with maximum visibility provided through packaging. This was corroborated by the study of Hurley et al (2013). In their experiment, a product was offered to the participants while shopping, in four different types of packaging that exposed it in a different amount $(0 \%, 40 \%$, $90 \%, 100 \%)$. The participants preferred the packaging that entirely exposed the product. Mentioned research presents groundwork for the hypotheses that guided our study. The first one is related to the tendency of a consumer to choose transparent packaging and it says:

$\mathrm{H}_{1}$ : Users prefer the packaging which completely exposes the product.

The perception of food healthiness can also be determined by packaging and its ability to represent the content that is inside of it. In the context of food healthiness, the research (Riley, Martins da Silva, \& Behr, 2015) showed that users preferred the picture of the product over the transparent window on the packaging, since it was considered to be more visually attractive. Decrease in attractiveness in the case of transparent packaging was also found in the study of Vilnai-Yavetz and Koren (2013) where it was shown that transparent packaging is perceived as less aesthetic. By connecting these findings with the previously mentioned research (Deng \& Srinivasan, 2013) that pointed out the importance of the product type while analysing the influence of transparency, the second hypothesis was formulated:

$\mathrm{H}_{2}$ : Users rate the non-transparent packaging as more attractive in the case of healthy food.

\section{Methodology}

The research was conducted in two ways. The first one referred to the hypothesis $H_{1}$, with focus on preferences, and was based on choice-task. The second one referred to the hypothesis $\mathrm{H}_{2}$, with focus on attractiveness, and was based on the participants' subjective evaluation.

\section{Participants}

The participants have been chosen randomly, keeping in mind to include approximately the same number of women and men. Only people of 18 and older were considered for the research, presuming that people from that age and upward did their shopping by themselves. 72 examinees, aged 23-52, participated in the research. $64 \%$ were women, and the rest, men. Both studies included the same participants.

\section{Samples}

The packaging was designed for two types of product produced by a fictional company „Mendella“. The first type were cereals, representing healthy food. The second type were sweets, representing unhealthy food. Beside the product category, packaging samples also varied in transparency levels. Transparency varied at 4 levels- fully transparent packaging, packaging with two windows, packaging with one window, and non-transparent packaging. The samples are shown in Figure 1 and Figure 2.

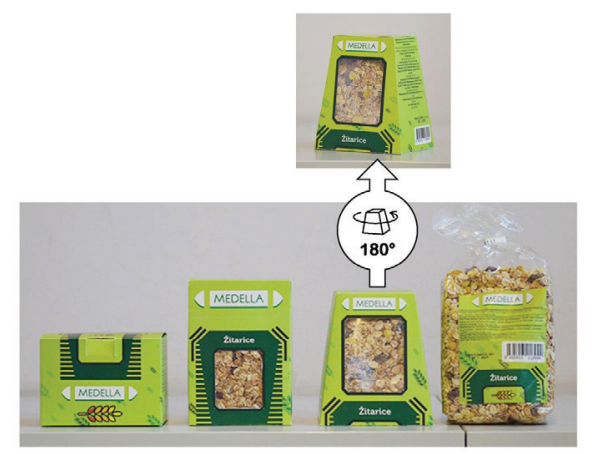

» Figure 1: Packaging samples for the healthy products

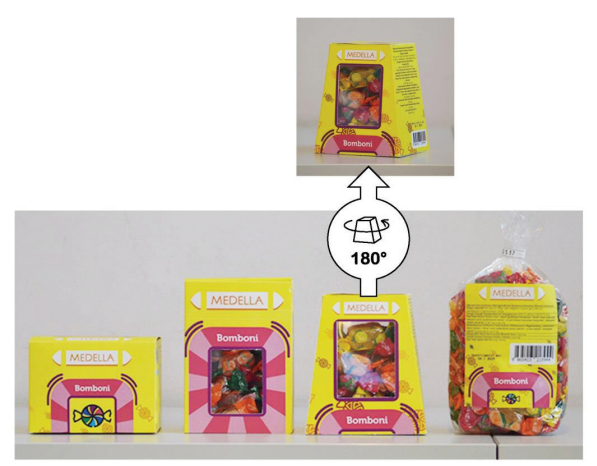

» Figure 2: Packaging samples for the unhealthy products 


\section{Procedure}

In the first study (choice-task), the participants were asked to choose between 4 products and decide which one they would opt for if they were in an actual store. The packaging varied in shape and size (which were not controlled variables), and this made the amount of product vary too, so the participants were previously asked to disregard that aspect. They were also asked to pay no attention to the price, so it wouldn't affect their choice. During decision making, the participants were not time limited.

In the second study (subjective evaluation), a five point Likert scale questionnaire was used for the participants to estimate attractiveness of the packaging. Value 1 represented "completely unattractive", and 5 represented "completely attractive". The participants were instructed that they can touch, look over and compare the products as long as they want to, but in the moment when they were given the questionnaire, they were asked to answer in regard to their primary reaction.

\section{Results}

For the choice task, participants' frequencies of choices for each packaging type are given in Table 1. The results are grouped by food type. The difference between these two groups was not significant ( $p=0.73$ by the Wilcoxon test). In both cases, the participants mostly preferred the packaging with transparency properties, while non-transparent packaging samples were mostly ignored. Cochran's $Q$ test shown that these differences were significant $(Q=34.89, d f=3, p<0.0001)$. While comparing fully transparent packaging with other less transparent packaging samples (i.e. packaging with one or two windows and non-transparent packaging), McNemar's test has shown that fully transparent packaging was preferred significantly more often than non-transparent $\left(\chi^{2}=33.02, p<0.0001\right)$. However, there were no significant differences in preferences between fully transparent packaging and packaging with two windows $\left(\chi^{2}=\right.$ $0.90, p=0.34)$, or with one window $\left(\chi^{2}=0.01, p=0.92\right)$.

The Friedman test revealed significant differences in attractiveness for the investigated packaging samples in the case of cereals $\left(\chi^{2}=72.16, d f=3, p<0.0001\right)$, as well as in the case of sweets $\left(\chi^{2}=56.19, d f=3, p<0.0001\right)$. Comparisons between each packaging sample were performed using a post hoc Wilcoxon test with Bonferroni's correction, so only the $\mathrm{p}$-values below 0.01 were considered significant. The results are shown in Table 2 . In the case of cereals, the non-transparent packaging was significantly less rated ( $M=1.89, S D=0.93)$ than fully transparent packaging $(\mathrm{M}=3.51, \mathrm{SD}=1.16)$, packaging with one window $(M=3.53, S D=1.22)$ and packaging with two windows $(M=3.26, S D=1.13)$, indicating that healthy food in non-transparent packaging is less attrac- tive to participants. In the case of sweets, the non-transparent packaging was also significantly less rated $(M=$ $2.18, S D=1.20)$ than fully transparent packaging $(M=$ $3.33, S D=1.29)$, packaging with one window $(M=3.69$, $S D=1.15)$ and packaging with two windows $(M=3.36$, $S D=1.03$ ), indicating that less healthy food in non-transparent packaging is less attractive to participants.

Table 1

Participants' choices of the packaging $(N=72)$

\begin{tabular}{c|c|c|c|c}
\hline & $\begin{array}{c}\text { Fully } \\
\text { transparent }\end{array}$ & Two windows & One window & $\begin{array}{c}\text { Non- } \\
\text { transparent }\end{array}$ \\
\hline Cereals & 26 & 21 & 22 & 3 \\
\hline Sweets & 24 & 19 & 26 & 3 \\
\hline
\end{tabular}

Table 2

Wilcoxon Signed Ranks Test

\begin{tabular}{|c|c|c|c|c|c|c|}
\hline & \multicolumn{3}{|c|}{ Cereals } & \multicolumn{3}{|c|}{ Sweets } \\
\hline & $\begin{array}{c}\text { Fully } \\
\text { transparent } \\
- \\
\text { Non- } \\
\text { transparent }\end{array}$ & $\begin{array}{c}\text { Two } \\
\text { windows } \\
- \\
\text { Non- } \\
\text { transparent }\end{array}$ & $\begin{array}{c}\text { One } \\
\text { window } \\
- \\
\text { Non- } \\
\text { transparent }\end{array}$ & $\begin{array}{c}\text { Fully } \\
\text { transparent } \\
- \\
\text { Non- } \\
\text { transparent }\end{array}$ & $\begin{array}{c}\text { Two } \\
\text { windows } \\
- \\
\text { Non- } \\
\text { transparent }\end{array}$ & $\begin{array}{c}\text { One } \\
\text { window } \\
- \\
\text { Non- } \\
\text { transparent }\end{array}$ \\
\hline Z & -5.85 & -5.20 & -6.59 & -4.36 & -5.34 & -6.22 \\
\hline $\mathbf{p}$ & 0.000 & 0.000 & 0.000 & 0.000 & 0.000 & 0.000 \\
\hline
\end{tabular}

\section{Discussion}

When it comes to consumer preferences during buying decision process, the results have shown that users are more inclined to choose transparent packaging, but not necessarily the one that shows the product completely, which is reason to reject the first hypothesis $\mathrm{H}_{1}$. On the other hand, completely non-transparent packaging was the least preferred. That kind of packaging had undoubtedly the lowest frequency of selection in the choice task and it has the lowest average rate when it comes to the subjective evaluation. A negative impact of non-transparency on the attractiveness of the product was expected considering previous studies that show how buyers find the possibility of visually checking the product very important (Dantas et al, 2004; Parhizgar \& Rostami, 2014). In line with that, the impossibility of that kind of check-up was rated significantly lower than semi or full transparency.

The second experiment showed that difference in healthiness of the sample groups didn't have any significant role in users' choice, although in Deng's and Srinivasan's study (2013) it was listed as one of the variables that can have the impact on consumer preferences. Moreover, it was shown that there is no significant difference in packaging attractiveness according to the type of the product that was in it. The results indicate that the second hypothesis $\mathrm{H}_{2}$ was rejected as well. In the case of healthy food, participants rated non-trans- 
parent packaging as the least attractive. They found transparent packaging as more appealing, which is in accordance with some previous studies that reported about the importance of product visibility during product evaluation (Parhizgar \& Rostami, 2014; Vilnai-Yavetz \& Koren, 2013). In our study, this can be ascribed to the participants' preferences based on the former experience since transparent packaging is the most common form of healthy food packaging in the stores.

Although hypotheses were rejected, the research question was answered. The goal was to investigate if there is any significant difference in consumer preference between different degrees of transparency, also considering the type of the product in it. Answer that arises from this research is that, during decision making process, users ignore non-transparent packaging more. Furthermore, the type of the product has no role in their preference towards transparent packaging.

\section{Conclusions}

This study investigated the level of product attractiveness in relation to the degree of packaging transparency and the food type. Results indicated that transparency affect the attractiveness of the product. On the other hand, the type of a product does not have a significant role in appeal rating, at least when it comes to the products used in our research with healthy cereals and unhealthy sweets. The attractiveness is the first step towards buying a product, so it is important to demonstrate which variables have impact on it. By isolating some other variables, this research gives the insight into the specificity of the one aspect of product appeal - packaging transparency. In conjugation with other empirical findings, mainly in the field of marketing and consumer research, our results can provide more substantial picture of how end users perceive specific food products.

Further research should use other various types of products in each category and include more variables related to users' preferences of the packaging. Furthermore, future research should be based on specific types of the realization the transparency of packaging, including irregular transparent shapes incorporated into design rather than just a surface size of the packaging.

\section{References}

Ares, G. \& Deliza, R. (2010) Studying the influence of package shape and colour on consumer expectations of milk desserts using word association and conjoint analysis. Food Quality and Preference. 21 (8), 930-937. Available from: doi: 10.1016/j.foodqual.2010.03.006 [Accessed 7th April 2017].
Becker, L., van Rompay, T. J. L., Schifferstein, H. N. J., \& Galetzka, M. (2011) Tough package, strong taste: The influence of packaging design on taste impressions and product evaluations. Food Quality and Preference. 22 (1), 17-23. Available from: doi: 10.1016/j. foodqual.2010.06.007 [Accessed 23rd April 2017].

Chandran, S., Batra, R. K., \& Lawrence, B. (2009) Is Seeing Believing? Consumer Responses to Opacity of Product Packaging. In: McGill, A.L., Shavitt, S. (eds.) ACR 2009 "A World of Knowledge At the Point of Confluence": NA - Advances in Consumer Research (Vol. 36), 22-25 October 2009, Pittsburgh, Pennsylvania. Duluth, Association for Consumer Research. p. 970.

Clement, J., Kristensen, T., \& Grønhaug, K. (2013) Understanding consumers' in-store visual perception: The influence of package design features on visual attention. Journal of Retailing and Consumer Services. 20 (2), 234-239. Available from: doi: 10.1016/j. jretconser.2013.01.003 [Accessed 15th April 2017].

Dantas, M. I. S., Minim, V. P. R., Deliza, R., \& Puschmann, R. (2004) The effect of packaging on the perception of minimally processed products. Journal of International Food \& Agribusiness Marketing. 16 (2), 71-83. Available from: doi: 10.1300/ J047v16n02_05 [Accessed 18th April 2017].

Deng, X., \& Srinivasan, R. (2013) When Do Transparent Packages Increase (or Decrease) Food Consumption? Journal of Marketing. 77 (4), 104-117. Available from: doi: 10.1509/jm.11.0610 [Accessed 1st May 2017].

Hurley, R. A., Galvarino, J., Thackston, E., Ouzts, A., \& Pham, A. (2013) The effect of modifying structure to display product versus graphical representation on packaging. Packaging Technology and Science. 26 (8), 453-460. Available from: doi: 10.1002/pts.1996 [Accessed 5th May 2017].

Karnal, N., Machiels, C. J. A., Orth, U. R., \& Mai, R. (2016) Healthy by design, but only when in focus: Communicating non-verbal health cues through symbolic meaning in packaging. Food Quality and Preference. 52, 106-119. Available from: doi: 10.1016/j. foodqual.2016.04.004 [Accessed 14th May 2017].

Kim, M. K., \& Lee, K.-G. (2015) Influences of intrinsic and extrinsic factors on consumer acceptance of orange juice using consumer liking testing and Kano analysis techniques. Food Science and Biotechnology. 24 (5), 1687-1693. Available from: doi: 10.1007/ s10068-015-0219-4 [Accessed 3rd June 2017].

Metcalf, L., Hess, J. S., Danes, J. E., \& Singh, J. (2012) A mixed-methods approach for designing market-driven packaging. Qualitative Market Research: An International Journal. 15 (3), 268-289. Available from: 10.1108/13522751211231987 [Accessed 22nd May 2017].

Parhizgar, M. M., \& Rostami, E. S. (2014) Packaging as brand communication: The impact of product display and advertising slogan on consumer's responses to the package and brand. International Journal of Basic Sciences \& Applied Research. 3, 21-27. 
Available from: http://isicenter.org/fulltext2/paper28022015092010.pdf [Accessed 10th May 2017].

Riley, D., Martins da Silva, P., \& Behr, S. (2015) The impact of packaging design on health product perceptions. In: Constantinescu, M., Barbu, A. M., Căescu, S. C., Angheluță, A. V., Tatu, C. I. \& Onișor, L. F. (eds.) MBD 2015: International Conference "Marketing and Business Development": Journal of International Conference on Marketing \& Business Development (Vol. 1, No. 1/2015), 25-27 June 2015, Bucharest, Hungary. Bucharest: Bucharest University of Economic Studies Publishing House. pp. 81-89.

van Ooijen, I., Fransen, M. L., Verlegh, P. W. J., \& Smit, E. G. (2017) Signalling product healthiness through symbolic package cues: Effects of package shape and goal congruence on consumer behaviour. Appetite. 109, 73-82. Available from: doi: 10.1016/j.appet.2016.11.021 [Accessed 24th April 2017].

Venter, K., Van der Merwe, D., De Beer, H., Kempen, E., \& Bosman, M. (2011) Consumers' perceptions of food packaging: An exploratory investigation in Potchefstroom, South Africa. International Journal of Consumer Studies. 35 (3), 273-281. Available from: doi: 10.1111/j.14706431.2010.00936.x [Accessed 7th April 2017].
Vilnai-Yavetz, I., \& Koren, R. (2013) Cutting through the clutter: Purchase intentions as a function of packaging instrumentality, aesthetics, and symbolism. The International Review of Retail, Distribution and Consumer Research. 23 (4), 394-417. Available from: doi: 10.1080/09593969.2013.792743 [Accessed 10th April 2017].

Wang, E.S.T. (2013) The influence of visual packaging design on perceived food product quality, value, and brand preference. International Journal of Retail \& Distribution Management. 41 (10), 805-816. Available from: doi: 10.1108/ IJRDM-12-2012-0113 [Accessed 10th April 2017].

Wasowicz-Kirylo, G., \& Stysko-Kunkowska, M. (2011) Attributes of nutritional information labelling that determine attractiveness of labels and correctness of inferences made about food healthfulness. Procedia - Social and Behavioral Sciences. 30, 722-728. Available from: doi: 10.1016/j. sbspro.2011.10.141 [Accessed 3rd May 2017].

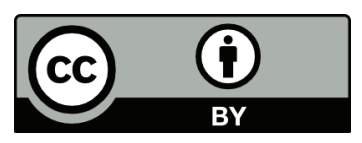

(c) 2017 Authors. Published by the University of Novi Sad, Faculty of Technical Sciences, Department of Graphic Engineering and Design. This article is an open access article distributed under the terms and conditions of the Creative Commons Attribution license 3.0 Serbia (http://creativecommons.org/licenses/by/3.0/rs/). 